\title{
Enhanced Practical Wireless Communications Education via Blended Instructional Tools
}

\author{
http://dx.doi.org/10.3991/ijim.v7i2.2477
}

\author{
Ashraf Tahat ${ }^{1}$, Ahmad Jamal ${ }^{2}$, Mohammad Kalbouneh ${ }^{1}$ \\ ${ }^{1}$ Princess Sumaya University for Technology, Amman, Jordan \\ 2 Umniah Mobile Telecommunications, Amman, Jordan
}

\begin{abstract}
Today's graduating telecommunications engineers need marketable skills that are typically developed beyond the traditional classrooms. These skills set can be acquired by experimenting for hands-on experience that resembles the professional field workplace. In this paper, we address blending of methodologies, applications, and the use of the Internet for delivery of knowledge, and instruction in an undergraduate wireless communications engineering course. This solution combines several different delivery methods, such as faceto-face, team collaboration, field measurements, in conjunction with high-end professional simulation software. Two examples of handover in a dual-mode cellular network and radio frequency (RF) signal propagation modeling are considered. Demonstrations and verification of theoretical models are presented based-on blending of instructional means. Lessons are learned to enhance hands-on experiments beyond traditional laboratories to strengthen in-depth analysis, learning skills of students, in addition to promoting proper team collaboration on projects.
\end{abstract}

Index Terms-Blended learning, handover, hand-off, handson laboratory, m-learning, 3G, GSM.

\section{INTRODUCTION}

Revelutionary advances in technology have driven the academic field to undergo a variety of corresponding significant changes to cope with the demands of the modern industry and workplace. Hence, classroom lectures on a particular advanced technical concept, such as wireless radio frequency fundamentals; need to be complemented at times by experimental illustrations. Because wireless communications related courses include topics that constitute techniques used in industries such as voice communications, data telecommunications systems [1], security systems, telemedicine and eHealth applications [2], ECO driving in conjunction with automotive maintenance [3], and defense systems, it is imperative for those industries that technical staffs such as engineers and technicians have the practical hands-on experience in addition to the theoretical background in wireless communications. Although laboratory experimentation form an invaluable supplement to theory in training of engineers and technicians, it falls short in many live field scenarios where in-depth understanding of some fundamental principles is vital for practical reallife network designs. Moreover, in most of educational institutions and training schools, there are several wireless communications courses for teaching the theoretical concepts, but no or not enough laboratory equipment to demonstrate or verify the application of the theory [4]. The main reason is that the equipment required in high-frequency wireless or radio communications laboratories are of significantly complex technology, and expensive. Hence, small to mid-size educational institutions cannot afford to obtain such equipment, and establish those hands-on experimental laboratories [5].

Undoubtedly, some of the countless opportunities modern technologies provide lie in the effective use of applications software and the Internet as potent instructional tools [6]. A simulation software-based laboratory, with experiments carried out on professional high-end planning and simulation software (e.g., ASSET3G by Aircom International) [7], could be used alone to replace field experiments by creating virtual simulations of desired scenarios within the capabilities of the deployed software. However, in the context of mobile RF field environment, simulation-based experiments always present an approximated and idealized result that can have a significant discrepancy from actual real-life field set-ups that exist in a live network.

A blending of a variety of low-cost learning tools and different delivery methods (such as collaboration in experimental field campaigns, simulation software, Internet-based applications, and m-learning [8], in addition to traditional instructional means) could provide for means to alleviate the previously described issues [6]. This has great resemblance to what is termed "blended learning," which refers to the combination of various event-based learning activities, including face-to-face classrooms, live e-learning, team collaboration, and asynchronous self-study [9].

In this paper, we consider two example fundamental concepts from a wireless communications engineering course, namely handover and wireless signal propagation [10], to illustrate the concrete application of the proposed learning approach [6]. This is carried-out as follows: Firstly, students learn the theory and engineering models of the above wireless phenomena through face-to-face instruction. Secondly, they form teams to go on field measurement campaigns to collect relevant data from three cellular sites (urban, suburban, rural) utilizing lowcost mobile application installed on their smart-phones. Thirdly, the collected data is exported into a special wireless network simulation and design software in a laboratory to perform simulations [11]. Finally, analysis and comparisons are performed to verify the studied fundamental theoretical concepts. 


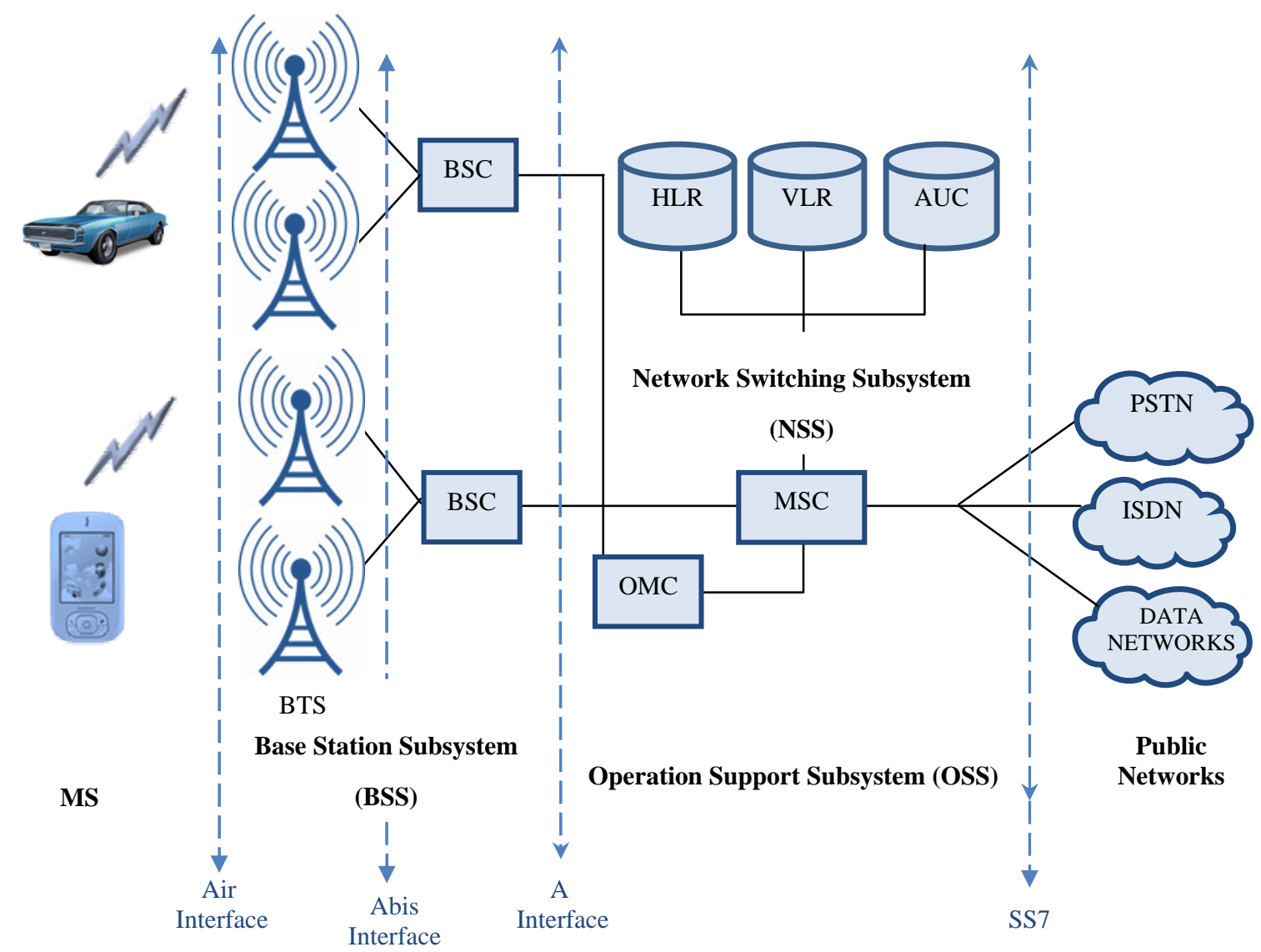

Figure 1. GSM network architecture

This paper is organized as follows: in section II, we review relevant cellular (wireless) concepts and models, and in section III we present the utilized measurement and visualization tools. In section IV, we describe simulation set-up and analysis. Finally, we conclude in section V.

\section{THEORETICAL BACKGROUND}

Dual-mode WCDMA-GSM mobile terminals require an interworking mechanism between the WCDMA and GSM technologies [10], [12]. For instance, if the user has established a voice call using WCDMA technology, and then moves outside of WCDMA coverage, the voice call needs to be handed over to GSM without any perceived disturbance during handover using dual-mode mobile station (MS) in a live network. Handover (hand-off) plays an instrumental role in ensuring interworking between WCDMA and GSM technologies.

\section{A. GSM Mobile System Architechure}

GSM (Global System for Mobile communication) is a digital mobile telephony system that is the most widely used mobile (cellular) radio communications standard in all parts of the world [13]. GSM uses a variation of time division multiple access (TDMA) where it digitizes and compresses a subscriber's data, then sends it down a channel with other streams of other users' data, each in its own time slot. A $200 \mathrm{kHz}$ carrier is divided into timeslots for individual phones to use. This allows eight full-rate or sixteen half-rate speech channels per carrier radio frequency. These eight radio timeslots (or eight burst periods) are grouped into a TDMA frame. The channel data rate for all 8 channels is $270.833 \mathrm{kbit} / \mathrm{s}$, and the frame duration is $4.615 \mathrm{~ms}$. GSM is typically deployed at either the $900 \mathrm{MHz}$ or $1800 \mathrm{MHz}$ frequency bands. While in North America, the $850 \mathrm{MHz}$ and $1900 \mathrm{MHz}$ bands were already allocated instead [10]. And in rare cases the 400 and $450 \mathrm{MHz}$ frequency bands are assigned in some countries because they were previously used for firstgeneration systems. Regardless of the frequency selected by an operator, the transmission power in the MS is limited to a maximum of 2 watts in GSM850/900 and 1 watt in GSM1800/1900 phones.

The GSM network is structured into a number of discrete sections as depicted in Fig. 1: a) The Base Station Subsystem (BSS) (the base stations and their controllers). b) The Network and Switching Subsystem (NSS) (the part of the network most similar to a fixed network). This is sometimes also just called the core network. c) The operations support system (OSS) for maintenance of the network. d) The GPRS Core Network (the optional part which allows packet based Internet connections).

\section{B. $3 G$ (WCDMA) Mobile Network Architechutre}

Third-generation mobile services are still now being deployed throughout the world [13]. Wideband codedivision multiple access (WCDMA) technology is an excellent framework for providing multimedia services, since it meets the performance demands of the mobile Internet, including Web access, audio and video streaming, ing, and video and IP multimedia calls [10]. 


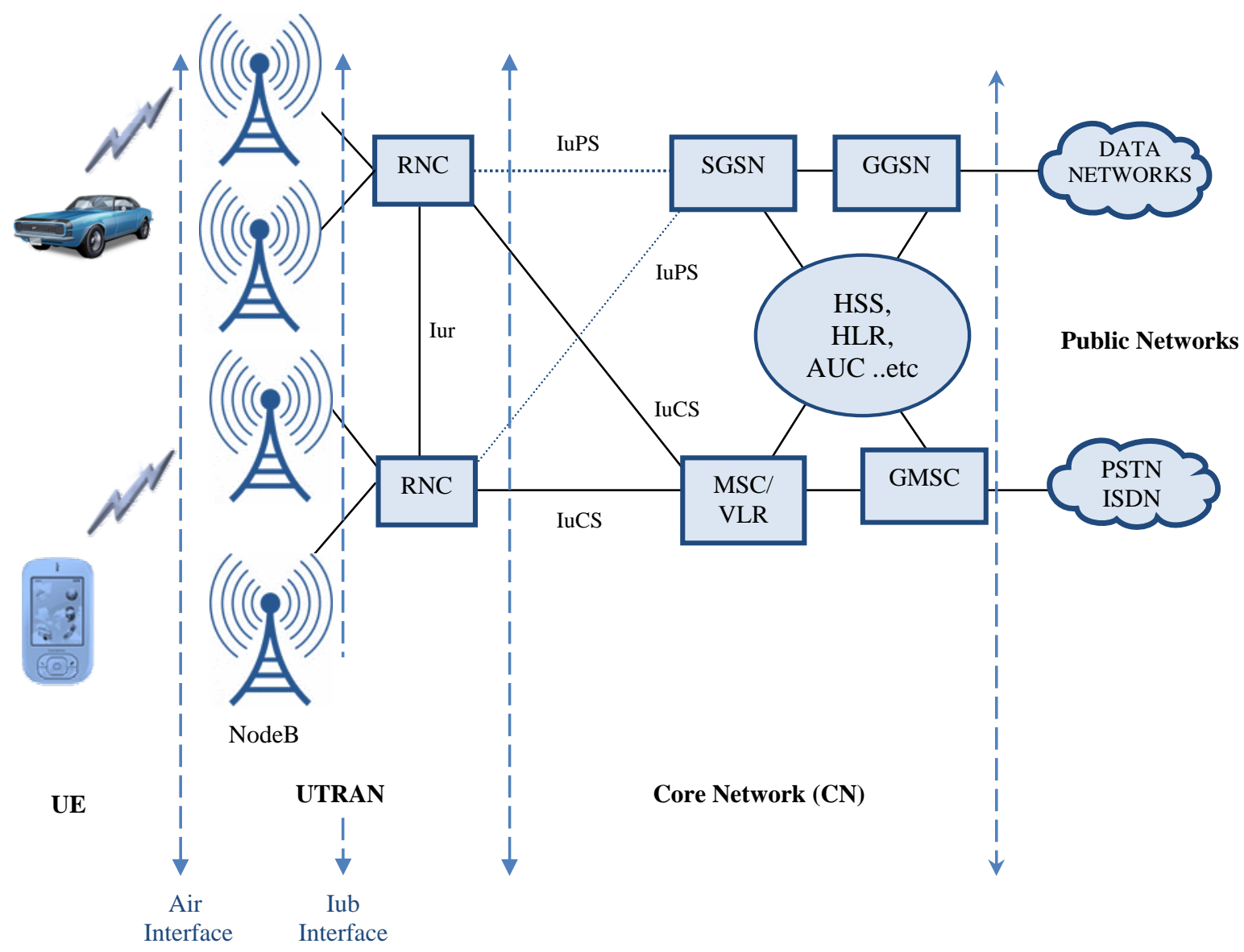

Figure 2. 3G UMTS network architecture

WCDMA transmits on a pair of $5 \mathrm{MHz}$-wide radio channels and uses direct sequence CDMA transmission technique unlike GSM that uses TDMA.

Services advertised as $3 \mathrm{G}$ are required to meet IMT2000 technical standards. Recent 3G releases, often denoted $3.5 \mathrm{G}$ and $3.75 \mathrm{G}$, provide mobile broadband access of several megabits per second to smartphones and mobile modems in laptop computers. While most WCDMA technology will initially only be deployed to cover urban areas, GSM networks have a nationwide or global footprint that provides access to mobile services, such as voice, data, short message service (SMS) and multimedia messaging service (MMS). Therefore, operators who already have a GSM network want to capitalize on their investments when migrating to WCDMA technology. A third-generation MS equipped with both WCDMA and GSM technology would put the end-user in contact with seamless, (practically) worldwide, mobile service. As depicted in Fig. 2, a UMTS network consist of three interacting domains: a) Core Network (CN) which contains the databases and network management functions b) UMTS Terrestrial Radio Access Network (UTRAN) c) User Equipment (UE). The basic Core Network structure is similar to the GSM network with GPRS. Base Station is referred to as NodeB, and control of NodeB's is performed through the Radio Network Controller (RNC).

\section{Handover Between 3G (WCDMA) and GSM Networks}

Handover between WCDMA and GSM allows the GSM network to be used to give fallback coverage for WCDMA technology. This means that subscribers can experience seamless services in an initial commercial launch. Although the network solely communicates with the mobile terminal using one access technology (GSM or WCDMA) at a time, the mobile terminal needs to perform measurements on GSM while communicating in WCDMA and vice versa [12].

The dual-mode mobile terminal reselects a GSM cell when that cell is ranked higher than the current WCDMA cell or any other WCDMA cell. WCDMA and GSM cells are ranked together according to signal strength. This same type of ranking applies in GSM. When performing cell re-selection in WCDMA, the mobile terminal either measures GSM cells continuously or when the quality of the serving WCDMA cell falls below a given threshold. The mobile terminal is solely allowed to select a new WCDMA or GSM cell when the average received quality and average signal strength exceed a minimum threshold [12]. The minimum-quality threshold (signal-to-noise ratio) ensures that the mobile terminal can receive the information transmitted by the potential target cell. This criterion also takes into account: a) The maximum transmit power that the mobile terminal is allowed to use 
PAPER

ENHANCED PRACTICAL WIRELESS COMMUNICATIONS EDUCATION VIA BLENDED INSTRUCTIONAL TOOLS

when accessing the cell. b) The maximum radio frequency (RF) output power that the mobile terminal can transmit.

\section{Wireless Signal Propagation Modeling}

One of the main important parameters required to ensure service is the received signal power. During planning, propagation models are utilized to predict path loss and received signal power. Propagation Models are mathematical attempts to model the 'real' radio environment as closely as possible. Most propagation models need to be tuned or calibrated by being compared to measured propagation data; otherwise you will not be able to obtain accurate coverage predications [14].

Several models have been developed to meet the requirements of realizing the propagation behavior in different conditions [10]. These models have been traditionally applied to frequencies below $2 \mathrm{GHz}$. According to Jordan's Telecommunications Regulatory Commission, the used propagation model in Amman, and Jordan in general, is COST 231 Hata for the frequency bands of $800 \mathrm{MHz}$ to $2100 \mathrm{MHz}$. UMTS site density is generally greater than GSM site density; hence accuracy in the first hundreds of meters from the base station is of high importance [14].

We used ASSET3G by Aircom International [7] to predict signal strength values of received power and to provide coverage maps based on these results. Base station configuration parameters and GIS digital map including clutter, elevation and vectors are needed for this process. The digital map of Amman, Jordan we have used had a $20 \mathrm{~m}$ resolution. We used the Standard Macrocell Model in ASSET3G [11] for estimating path loss. This is a slightly modified Okumura-Hata model [10]. The path Loss formula for this model is as follows [11]

$$
\begin{aligned}
P L_{M C}= & K_{1}+K_{2} \log _{10}(d)+K_{3} H_{m s}+K_{4} \log _{10}\left(H_{m s}\right)+\# \\
& K_{5} \log _{10}\left(H_{\text {eff }}\right)+K_{6} \log _{10}\left(H_{\text {eff }}\right) \log _{10}(d)+ \\
& K_{7}(\text { Diff })+C_{\text {loss }}
\end{aligned}
$$

where $d$ is the distance from the base station (BS) to the mobile station (MS) in kilometers, $H_{m s}$ is the height of the mobile station above ground in meters, $H_{\text {eff }}$ is the effective base station antenna in meters, diffn diffraction loss calculated using the Epstein-Peterson, Bullington, Deygout, or Japanese Atlas knife edge techniques. Table 1 lists the default $K$-parameters values for popular standard cellular frequencies. These values represent typical starting values based on urban environment. $C_{\text {Loss }}$ is clutter specifications such as heights and separation are also taken into account in the calculation process.

It is vital that the model has to be accurately calibrated (tuned) to correspond to real network environment to obtain more accurate prediction values for a real live project [14]. To do this, we need to compare predicted propagation data with student team survey data to produce an accurate propagation model that functions correctly and to be utilized by in-laboratory simulations.

TABLE 1

Default Propagation Model Parameter Values

\begin{tabular}{|l||l|l|l|}
\hline Parameter & $\mathbf{9 0 0} \mathbf{~ M H z}$ & $\mathbf{1 8 0 0} \mathbf{~ M H z}$ & $\mathbf{2 0 0 0} \mathbf{~ M H z}$ \\
\hline$K_{1}$ & 150.6 & 160.9 & 162.5 \\
\hline$K_{2}$ & 44.9 & 44.9 & 44.9 \\
\hline$K_{3}$ & -2.55 & -2.55 & -2.55 \\
\hline$K_{4}$ & 0.00 & 0.00 & 0.00 \\
\hline$K_{5}$ & -13.8 & -13.8 & -13.8 \\
\hline$K_{6}$ & -6.55 & -6.55 & -6.55 \\
\hline$K_{7}$ & 0.7 & 0.8 & 0.8 \\
\hline
\end{tabular}

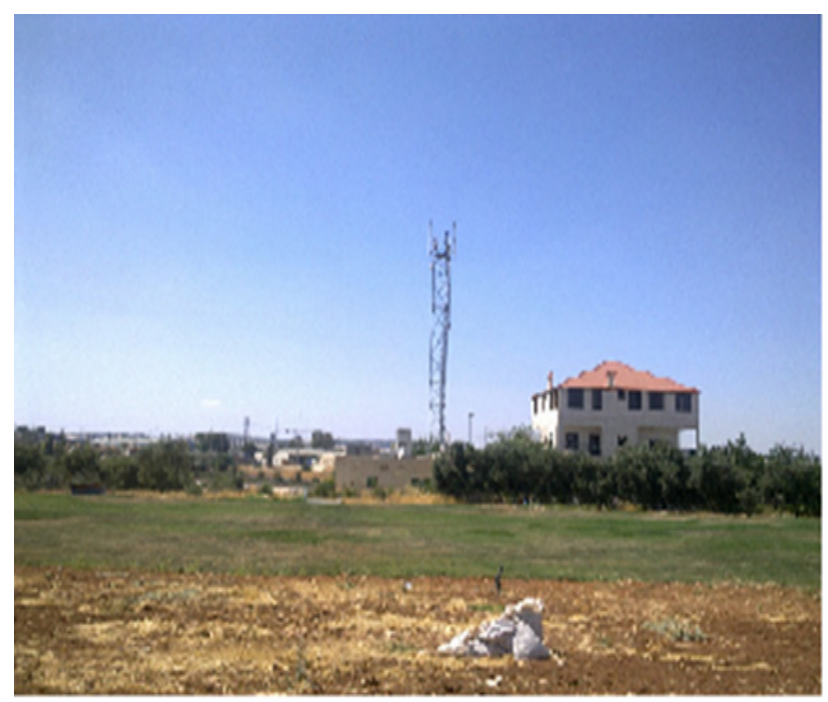

Figure 3. Photo of a GSM BS site location near QAIA road.

\section{FIELD MEASUREMENTS AND ANALYSIS TOOLS}

Firstly, the student measurement campaign was sent to identify areas near city limits were $3 G$ coverage starts to diminish and handover to a GSM BS with adjacent cell coverage becomes necessary. This utilized test-bed in a live network was set-up with a 3G system operating in the $2100 \mathrm{MHz}$ frequency band and GSM system operating in the $900 \mathrm{MHz}$ frequency band. The measurements were performed with one dual-mode mobile terminal connected to one BS at a time. The transmitted power for each BS was $33 \mathrm{dBm}$ for 3G, and the transmitted power for each GSM BS was $41 \mathrm{dBm}$.

Secondly, the signal propagation measurements campaign has collected readings at three different locations representing urban, suburban, and rural environments. Some measurements were close to a BS and some were near cell borders, taken in a gradually increasing manner. Selection of locations was based on various criteria, where distance, elevation, and line-ofsight (LOS) capabilities were the main differing attributes at each location.

Physical recorded measurements included the Received Signal Strength Indication (RSSI), GPS location coordinates, and a photo of the BS tower site. Fig. 3 shows a photo captured at the considered GSM site near Queen Alia International Airport (QAIA) road. GPS 
coordinates were tracked at each BS location, thus a terrain profile could be constructed to fully determine the obstacles that may interfere with LOS. Mobile application software CellTrack [15] version 9.1 was used on a Nokia X6 phone in this drive test procedure to take the measurements.

\section{A. CellTrack}

CellTrack is a mobile application software utilized to extract and collect some phone information about the serving cell it is connected to [15]. Fig. 4 shows the CellTrack application software interface running on the Nokia X6 phone. CellTrack provides the following parameters: Cellid the ID from the actual cell. LAC the Location Area Code from your cell. Net the network you are moving in ( e.g. 416 for Jordan and 77 for Orange Jordan). If a WCDMA/UMTS cell is present, it is also shown here. Name the name of the cell. This is shown by an algorithm when you select 'Cell Name from ID' in the settings, or from the cell broadcast when you have turnedon 'Cell Name from CBS' and have defined a service number. CBS overwrites the generated name. Signal shows the quality of the receive signal. The in a percentage value is taken from the phone API itself, while strength is displayed as a $\mathrm{dBm}$ value. Battery should show the capacity of your battery. Description shows information from the database. Diagram shows the $\mathrm{dBm}$ values as green and the percentage as a black line. The red lines represent cell changes. The equipment reported the RSSI values, which represent the received signal strength in $\mathrm{dBm}$.. When analyzing signal strength it is useful to relate the received signal strength to the distance between the BS and the SU. This section analyses the signal strength for the Down Link (DL). The physical measurements included only the RSSI. Sample measurements listed in Table 2 here were performed at each of a three selected locations by the subscriber station.

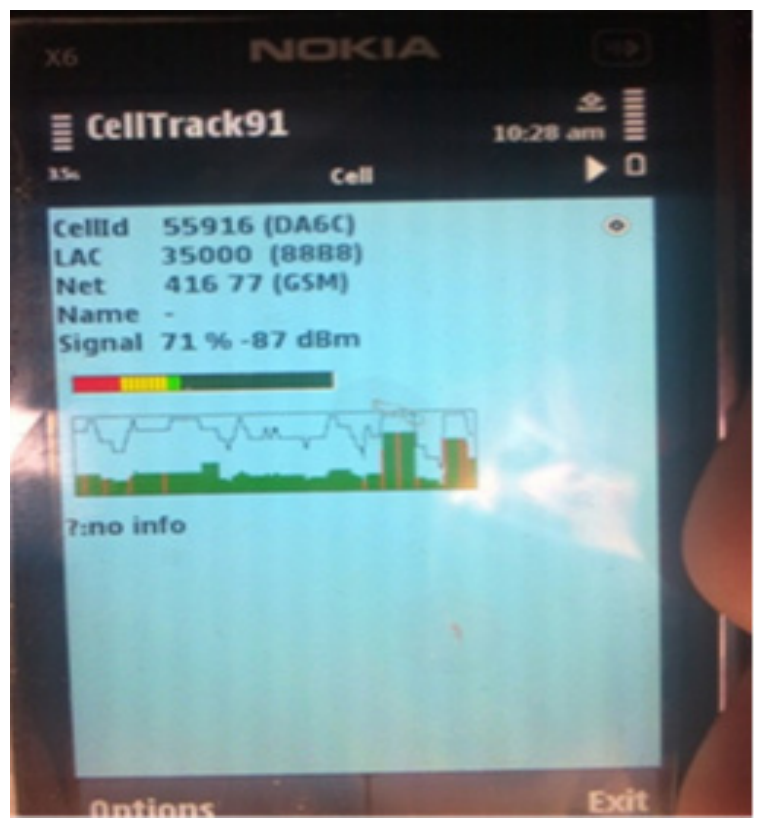

Figure 4. CellTrack mobile application software interface

The collected measurements for each site were tabulated in Excel ${ }^{\circledR}$ spreadsheets and then plotted. Fig. 5 shows a sample plot of measured data that depicts handover near the QAIA 3G and GSM sites indicating where handover has occurred from $3 G$ to the GSM site. We will show later generated plots of received signal power

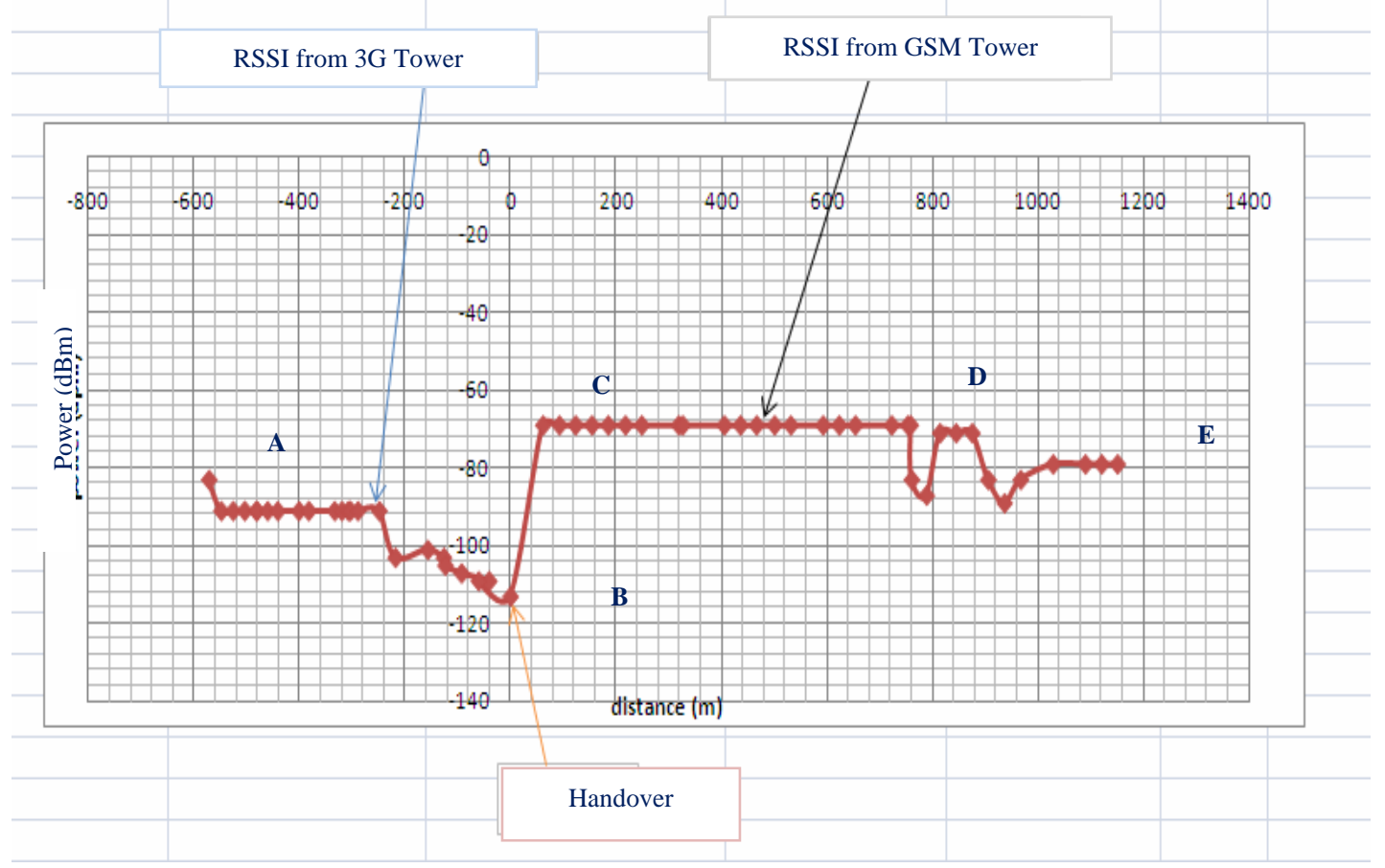

Figure 5. Plot of recorded measurements path between $3 G$ and GSM BS for QAIA locations. 
PAPER

ENHANCED PRACTICAL WIRELESS COMMUNICATIONS EDUCATION VIA BLENDED INSTRUCTIONAL TOOLS

TABLE 2

A SAMPLE OF RECORDED MEASUREMENTS AT TEST SiTES

\begin{tabular}{|c|c|c|c|}
\hline \multicolumn{5}{|c|}{ Site Readings- 3G and Header File - 3G } \\
\hline POINT & Longitude & Latitude & RSSI \\
\hline $\mathbf{1}$ & 35.88472222 & 32.0702777 & -79 \\
\hline $\mathbf{2}$ & 35.88333333 & 32.07083333 & -85 \\
\hline $\mathbf{3}$ & 35.88277778 & 32.07138889 & -79 \\
\hline $\mathbf{4}$ & 35.88222222 & 32.07166667 & -75 \\
\hline $\mathbf{5}$ & 35.87805556 & 32.07222222 & -85 \\
\hline $\mathbf{6}$ & 35.87777778 & 32.07222222 & -89 \\
\hline $\mathbf{7}$ & 35.87111111 & 32.06944444 & -69 \\
\hline $\mathbf{8}$ & 35.87722222 & 32.07222222 & -99 \\
\hline $\mathbf{9}$ & 35.87694444 & 32.07194444 & -89 \\
\hline $\mathbf{1 0}$ & 35.87666667 & 32.07166667 & -105 \\
\hline $\mathbf{1 1}$ & 35.87666667 & 32.07166667 & -110 \\
\hline $\mathbf{1 2}$ & 35.87638889 & 32.07138889 & -105 \\
\hline
\end{tabular}

(RSSI) and predicted values super imposed on the same plot to emphasize the value of this approach and appreciate the methodology in bringing a real feel of the physical phenomena.

\section{B. Google Earth}

Google Earth ${ }^{\circledR}$ is a virtual globe, map and geographical information software that was acquired by Google in 2004 [13], [16]. It maps the Earth by the superimposition of images obtained from satellite imagery, aerial photography and GIS 3D globe. Fig. 6 shows a sample Google Earth view of one of the considered test paths, QAIA, surrounding area and measurement locations superimposed using tags.

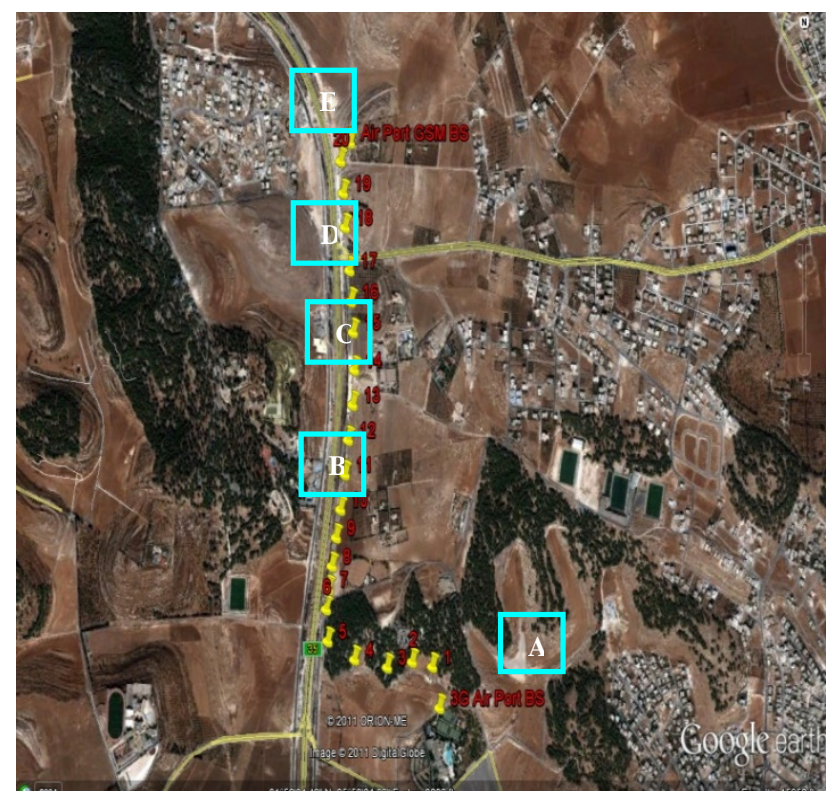

Figure 6. A Google Erath view of measurement locations.

Google Earth ${ }^{\circledR}$ is currently available for use on personal computers running Windows, Mac OS, or Linux operating systems, and is also available for mobile viewers as a free application [16]. It displays parts of the surface of the Earth in addition to availability of 3D images of terrain and buildings. It uses digital elevation model (DEM) data collected by NASA's Shuttle Radar Topography Mission (SRTM).

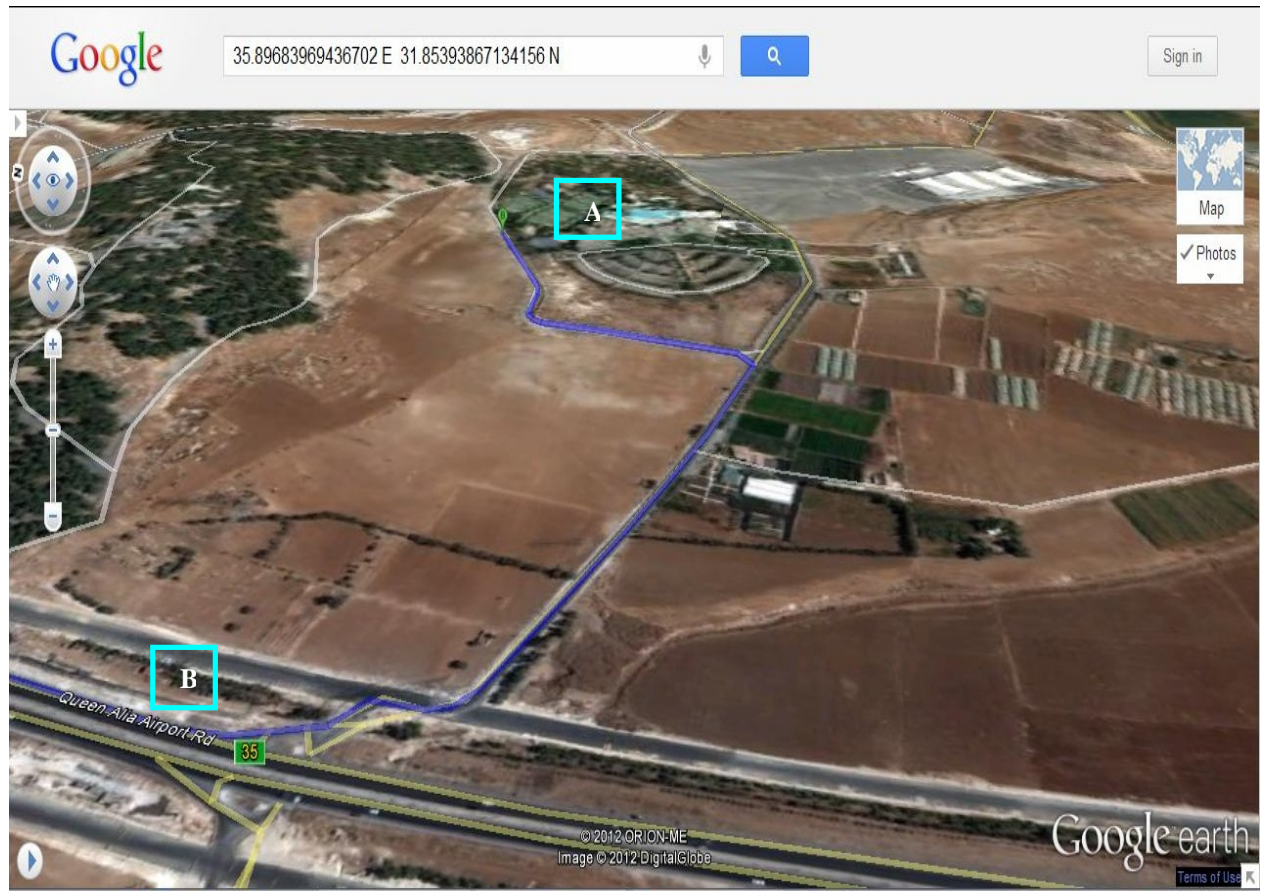

Figure 7. 3D earth view of the 3G BS site location near QAIA road. 
Google Earth can provide a lot of information about a location. However, the information is stored in layers, which can be turned on or off. Layers include roads, border labels, parks, ...etc. Two layers are useful for creating a more three dimensional globe: Terrain layer simulates the elevation levels, and the 3D Buildings layer lets you zoom through cities, and between buildings. 3D views of many mountains have been improved by the use of supplementary DEM data to fill the gaps in SRTM coverage [13]. Google Earth is also available as Web Map Service client. It supports managing threedimensional Geospatial data through Keyhole Markup Language (KML). It has the capability to show 3D structures, which consist of users' submissions using SketchUp, a 3D modeling program software. This means one can view the whole earth in three dimensions. Fig. 7. shows a 3D view of the 3G BS cell site near QAIA road.

\section{ASSET3G by Aircom International}

Several groups of measured data sets were imported into ASSET3G by Aircom International [7] using the InSignia standard file format [11] to calibrate relevant propagation models, predict signal strength values of received power, and to provide coverage maps based on these results and relying on base station configuration parameters in conjugation with GIS digital map as shown Fig. 8.

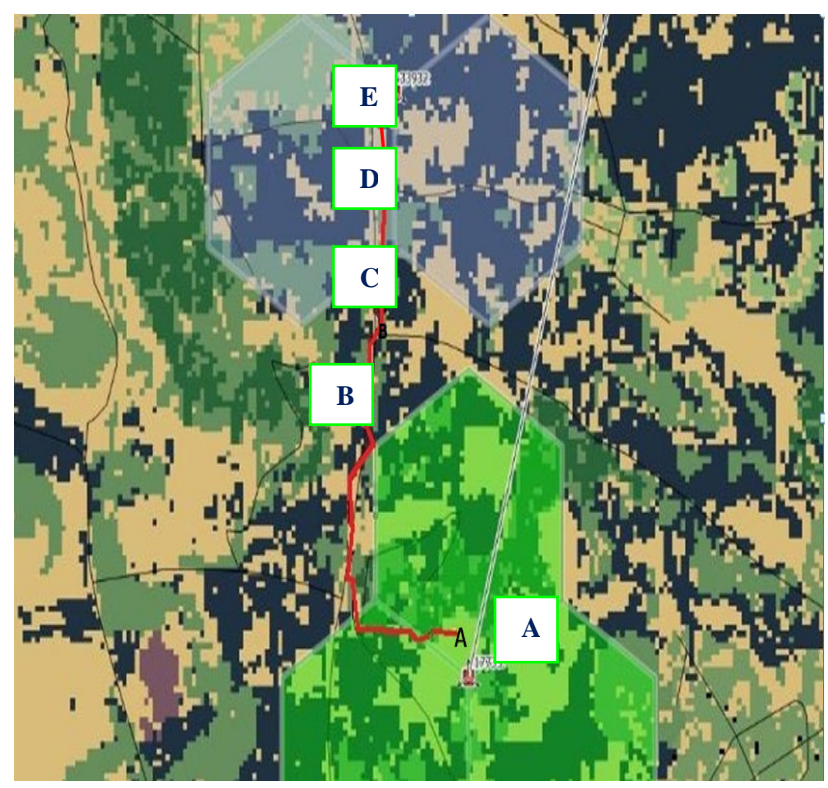

Figure 8. Measurement path between BS locations for QAIA sites in ASSET3G software.

\begin{tabular}{|c|c|c|c|c|c|c|}
\hline \multicolumn{3}{|c|}{ 3G Site Parameters } & \multicolumn{4}{|c|}{ GSM Site Parameters } \\
\hline \multicolumn{3}{|c|}{ Y-Model Calibration Uitiliy } & \multicolumn{4}{|c|}{ Y Model Calibration Utility } \\
\hline \multicolumn{3}{|c|}{ Fie Toos Cater Heb } & \multicolumn{4}{|c|}{ Fie Toos Cater Heb } \\
\hline \multicolumn{3}{|c|}{ Itto } & \multicolumn{4}{|c|}{ Itio } \\
\hline Canerbly losted fir & \multicolumn{2}{|c|}{ 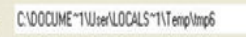 } & Canterty losided file & \multicolumn{3}{|c|}{ 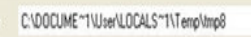 } \\
\hline \multicolumn{3}{|c|}{ 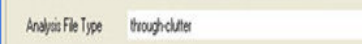 } & \multicolumn{2}{|c|}{ 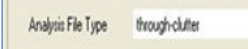 } & & \\
\hline \multicolumn{3}{|c|}{ 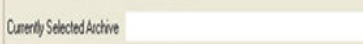 } & \multicolumn{4}{|l|}{ Canerebs Setected active } \\
\hline Inisusisution & Tunes Sulutios & Optrict Pranietes: & 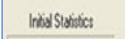 & Tunessustios & \multicolumn{2}{|c|}{ Opdriste Prorietes } \\
\hline MenEner & Mes Enor 0000 & Maslterdions 1100 & MesenEna 0.355 & Mean Enox 0000 & Marliero & exabon \\
\hline Sodoer & SHoder 8821 & ConvAcuncy $\longdiv { 0 0 0 1 }$ & SHDDer 149000 & SHDer 8784 & Com $\mathrm{ACO}$ & Accuracy $\longdiv { 0 0 0 1 }$ \\
\hline \multicolumn{3}{|c|}{ Hosp Pysinetess } & \multicolumn{4}{|c|}{ Hota Pasnetes: } \\
\hline \multirow{3}{*}{\multicolumn{2}{|c|}{ 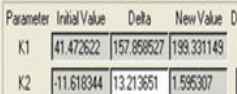 }} & \multirow{2}{*}{ Detarisoge fix } & \multirow{2}{*}{\multicolumn{2}{|c|}{ 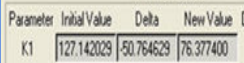 }} & \multicolumn{2}{|c|}{ Dela Rarge: Fi } \\
\hline & & & & & \multicolumn{2}{|c|}{ Chon } \\
\hline & & $-\sqrt{x} \Gamma$ & \multicolumn{2}{|c|}{ 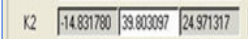 } & \multicolumn{2}{|c|}{$\sqrt{30} r$} \\
\hline $\mathrm{k} 3$ & Coniturs & & K3 & Conterts & \multirow{2}{*}{\multicolumn{2}{|c|}{ ד ד }} \\
\hline \multirow{2}{*}{$\begin{array}{l}\mathrm{KA} \\
\mathrm{K}\end{array}$} & Contersts & & \multicolumn{2}{|c|}{ K4 Contunts } & & \\
\hline & 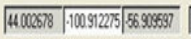 & $\Gamma$ & $1 5 \longdiv { - 1 1 3 0 4 5 6 }$ & 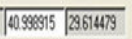 & $\sqrt{x}$ & $r$ \\
\hline K6 & 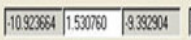 & $\Gamma$ & K6 $\longdiv { 9 4 5 5 2 6 5 }$ & 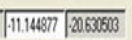 & 10 & $\Gamma$ \\
\hline 18 & $\sqrt { 0 1 3 5 3 4 5 } \longdiv { 0 . 5 0 1 5 5 5 } \longdiv { 0 . 3 5 2 1 9 }$ & $\Gamma$ & $1 7 \longdiv { 0 . 0 0 4 5 2 }$ & $\longdiv { 0 . 4 5 1 8 2 5 } \longdiv { 0 . 3 6 7 3 5 3 }$ & & r \\
\hline
\end{tabular}

Figure 9. Propagation model tuning (calibration) in ASSET3G software.

ASSET3G enables you to auto-tune your propagation models, using analysis-information from a comparison between your model's path-loss parameters predictions using default $K$ parameters of Table 1 and 'real-world' measurement data to find new $K$ parameters appropriate to each site's geographic area as shown in Fig. 9.

We show in Fig. 10 a plot of the actual measured received power in the coverage area of the GSM site. On the same graph, we plot the predicted received power using the ASSET3G planning and simulation software before propagation model tuning. Then superimposed on the same graph we plot the predicted received power after tuning the propagation model using the measurements campaign actual values. It is evident how the calibration process relying on field merriments is vital in obtaining predictions with significant accuracy for wireless network planning and optimization.

Now that we have calibrated (tuned) propagation models conforming to the environment we are working in (thanks to experimental data files), coverage footprints for each site is created after running the path-loss predictor to produce the coverage footprints for each considered site. Fig. 11 shows coverage map (RSSI) for the QAIA 3G and GSM sites. 
PAPER

ENHANCED PRACTICAL WIRELESS COMMUNICATIONS EDUCATION VIA BLENDED INSTRUCTIONAL TOOLS

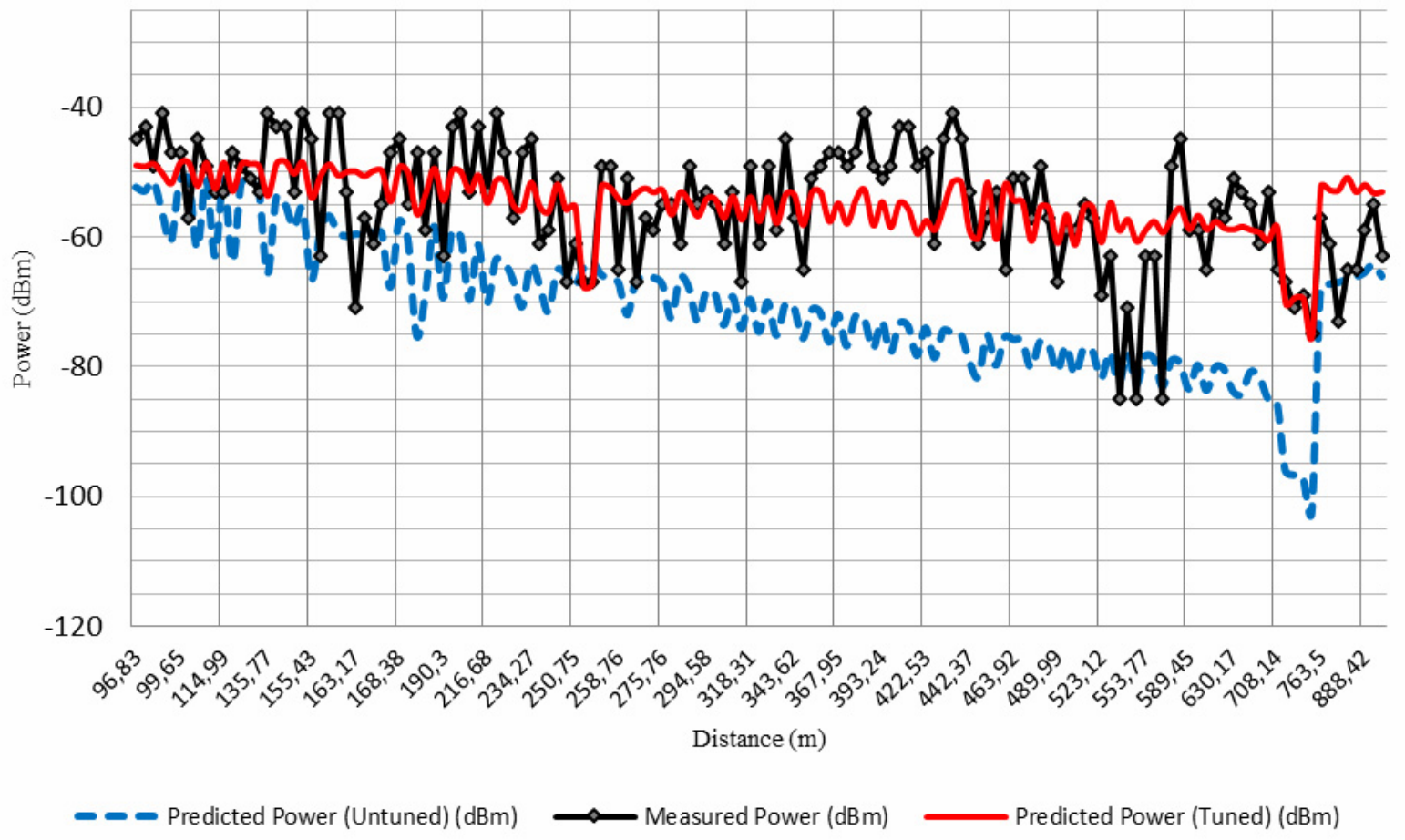

Figure 10. Measured and predicted RSSI for GSM 900MHz site before and after tuning near QAIA.

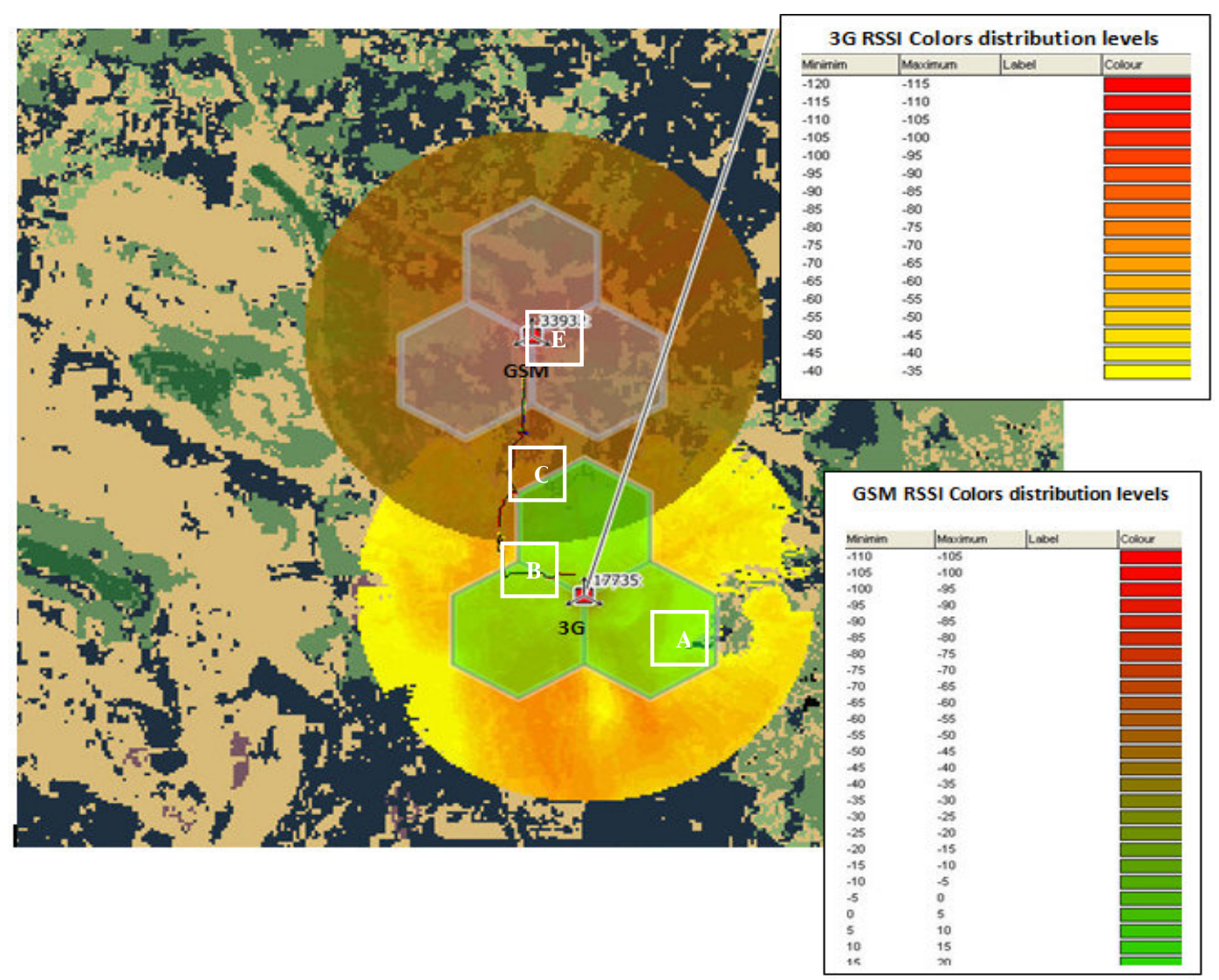

Figure 11. Simulated coverage of 3G and GSM sites in ASSET3G software near QAIA. 


\section{NEIGHBORING ANALYSIS IN ASSET3G}

Handovers can be classified into three categories [12]: Hard handovers which are intended to be instantaneous in order to minimize the disruption to the call. A hard handover is perceived by network engineers as an event during the call. When the mobile is between base stations cell borders, then the mobile can switch to any of the base stations, so the base stations bounce the link with the mobile back and forth. This is called pingponging. Soft handover is one in which the channel in the source cell is retained and used for a while in parallel with the channel in the target cell. The interval, during which the two connections are used in parallel, may be brief or substantial. Soft handovers may involve using connections to more than two cells (connections to three, four or more cells can be maintained by one phone at the same time). Softer handover occurs when a call is in a state of soft handover, the signal of the best of all used channels can be used for the call at a given moment or all the signals can be combined to produce a clearer copy of the signal. The latter is more advantageous. Such combining is performed both in the downlink (forward link) and the uplink (reverse link) in a softer handover scenario.

There are two ways to define neighboring cells "neighbors" to a certain base station, manual and automatic [11]. ASSET3G refers to the manual method with "Database", and for the automatic method with "Plan". The neighbor analysis feature in ASSET3G software can be used to view all the relationships currently existing in the Site Database.

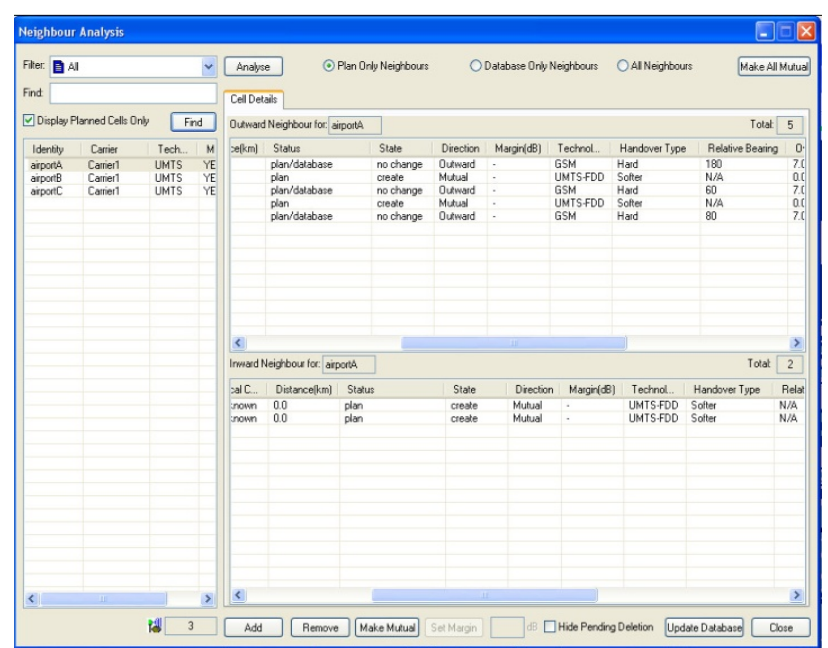

Figure 12. Neighboring analysis window in ASSET3G

You can also examine the differences, on a cell-bycell basis between the database and any new potential neighboring data that has been generated or loaded. As shown in the Fig. 12, at point B, QAIA sector A, performed a hard handover at distance $700 \mathrm{~m}$ away from the $3 G$ site to the GSM site.

Referring to Fig. 5, which represents a plot of the actual observed received power (RSSI) from either of the 3G or the GSM BS that the MS is currently connected to, indicates that a handover has occurred at approximately $1.3 \mathrm{~km}$ away from the $3 \mathrm{G}$ site to the GSM site. This is in agreement with what is predicted by ASSET3G neighbor analysis feature.

\section{CONCLUSIONS}

This paper has presented a blending methodology for a variety of learning (instructional) tools to provide for an inexpensive practical and hands-on learning approach in wireless communications course. This has proved to be effective for verification and for illustration of fundamental but hard to perceive concepts in mobile communications. Two examples, handover and RF signal propagation modeling, were presented and verified. In addition, these approaches emphasize students' collaborative work with their peers and active participation within educational framework.

\section{REFERENCES}

[1] A. Tahat, M. Khalaf, and O. Elmuhesen, "A solar energy water heater remote monitoring and control system," in Proc. International Conference on Electronic Devices, Systems, and Applications (ICEDSA), pp. 98-103, April 2011. http://dx.doi.org/10.1109/ICEDSA.2011.5959056

[2] A. Tahat, A. Sacca, and Y. Kheetan, "Design of an integrated mobile system to measure blood pressure," in Proc. IEEE $18^{\text {th }}$ Symposium on Communications and Vehicular Technology (SCVT), pp. 1-6, November 2011.

[3] A Tahat, A. Said, F. Jaouni, and W. Qadamani, "Android-based universal vehicle diagnostic and tracking system," in Proc. IEEE $16^{\text {th }}$ International Symposium on Consumer Electronics (ISCE), pp. 137-143, June 2012.

[4] A. Kara, E. Aydin, R. Oktem, and N. Cagiltay, "A remote laboratory for training in radio communications: ERRL," in Proce. The 18th IEEE International Symposium on Personal, Indoor and Mobile Radio Communications (PIMRC'07), pp. 1-6, August 2007.

[5] N. Cagiltay, E. Aydın, R. Oktem, A. Kara, M. Alexandru, and B. Reiner, "Requirements for remote RF laboratory applications: an educators' perspective,” IEEE Tran. on Education, vol. 52, pp. 75-81, February 2009. http://dx.doi.org/10.1109/TE.2008.919806

[6] A. Tahat, A. Jamal, M. Kalbouneh, and H Jaber, ”Blending of learning tools for enhanced practical wireless communications education," in Proc. $6^{\text {th }}$ Interactive Mobile \& Computer Aided Learning International Conference (IMCL), pp. 1-6, November 2012.

[7] Aircom International, http://www.aircominternational.com/, July 2012.

[8] J. Attewell, and M. Gustafsson, "Mobile communications technologies for young adult learning and skills development (mlearning)," in Proc. IEEE International Workshop on Wireless and Mobile Technologies in Education (WMTE '02), pp. 158-160, August2002. http://dx.doi.org/10.1109/WMTE.2002.1039240

[9] D. Garrison, and H. Kanuka, "Blended learning: Uncovering its transformative potential in higher education," The Internet and Higher Education , vol. 7, pp. 95-105, 2 2d quarter 2004.

[10] A. Molisch, Wireless Communications, $2^{\text {nd }}$ ed., West Sussex, England: Wiley \& Sons, Ltd., 2011.

[11] ASSET User Reference Guide, Version 6, AIRCOM International Ltd, Leatherhead, Surrey, UK, 2007.

[12] G. Alsenmyr et. al., "Handover between WCDMA and GSM," Ericson Review, No. 1, 2003.

[13] Wikiepedia, http://en.wikipedia.org/ July 2012.

[14] A. Tahat, and M. Taha, " Statistical tuning of Walfisch-Ikagami propagation model using particle swarm optimization," in Proc. $19^{\text {th }}$ IEEE Symposium on Communications and Vehicular Technology (SCVT) in the Benelux, pp. 1-6, November 2012.

[15] CellTrack, http://www.afischer-online.de/sos/celltrack/, May 2011.

[16] Google Earth, http://www.google.com/edu/teacher/ , July 2012 . 


\section{AUTHORS}

Dr. Ashraf Tahat received the B.S., M.S., and Ph.D. degrees in Electrical Engineering from the Illinois Institute of Technology (IIT), Chicago, Illinois, USA, in 1992, 1993, and 2002, respectively. He is an Associate Professor with the Department of Communications Engineering at PSUT in Amman, Jordan where he was the Department Chairman. He is currently a Visiting Professor in the Department of Electrical and Computer Engineering at McGill University in Montreal, Quebec, Canada, working on digital signal processing for modern communications systems such as LTE-A. In 2002, he worked at the ECE Department, IIT, as a Post-Doctoral Fellow. From 1998 to 2000, he was with 3Com Corporation working on voice-band PC modems. In 1997, he joined Lucent Technologies (AT\&T), Inc. (currently Alcatel-Lucent) as a consultant Research Engineer to assist in the development of DSP-based ADSL modems. Dr. Tahat is a senior member of IEEE. (e-mail: aat@ieee.org).
Ahmad Jamal received the BS degree in communications engineering from Princess Sumaya University for technology (PSUT) in Amman, Jordan in 2012. He is currently working at Umniah mobile communications copmany in Amman, Jordan as a Network Operator Engineer. He is responsible for command line configuration for Huawei/ZTE 3G \& 2G equipment, in addition to analysis and investigation of KPIs. (e-mail: ahmad_89@hotmail.com).

Mohammad Kalbouneh received the BS degree in communications engineering from Princess Sumaya University for technology (PSUT) in Amman, Jordan in 2012. He worked at Umniah mobile communications company in Amman, Jordan as a technical support engineer. (email: mohammad314278@yahoo.com )

This article is an extended and modified version of a paper presented at the the Interactive Mobile and Computer Aided Learning (IMCL2012), held in November 2012, at Princess Sumaya University for Technology, Amman, Jordan. Received 9 January 2013. Published as resubmitted by the author 20 March 2013. 